\title{
Ectopic Overexpression of Engrailed-2 in Cerebellar Purkinje Cells Causes Restricted Cell Loss and Retarded External Germinal Layer Development at Lobule Junctions
}

\author{
Stephan L. Baader, ${ }^{1}$ Salih Sanlioglu, ${ }^{1}$ Albert S. Berrebi, ${ }^{3}$ Jan Parker-Thornburg, ${ }^{1}$ and John Oberdick ${ }^{1,2}$ \\ ${ }^{1}$ The Neurobiotechnology Center, ${ }^{2}$ Department of Cell Biology, Neurobiology, and Anatomy/Neuroscience Division, The \\ Ohio State University, Columbus, Ohio 43210, and ${ }^{3}$ Departments of Otolaryngology and Anatomy-Head and Neck \\ Surgery, West Virginia University School of Medicine, Morgantown, West Virginia 26506-9200
}

\begin{abstract}
Members of the En and Wnt gene families seem to play a key role in the early specification of the brain territory that gives rise to the cerebellum, the midhindbrain junction. To analyze the possible continuous role of the En and Wnt signaling pathway in later cerebellar patterning and function, we expressed En-2 ectopically in Purkinje cells during late embryonic and postnatal cerebellar development. As a result of this expression, the cerebellum is greatly reduced in size, and Purkinje cell numbers throughout the cerebellum are reduced by more than one-third relative to normal animals. Detailed analysis of both adult and developing cerebella reveals a pattern of selectivity to the loss of Purkinje cells and other cerebellar neurons. This is observed as a general loss of prominence of cerebellar fissures that is highlighted by a total loss of sublobular fissures. In contrast,
\end{abstract}

mediolateral patterning is generally only subtly affected. That En-2 overexpression selectively affects Purkinje cells in the transition zone between lobules is evidenced by direct observation of selective Purkinje cell loss in certain fissures and by the observation that growth and migration of the external germinal layer (EGL) is selectively retarded in the deep fissures during early postnatal development. Thus, in addition to demonstrating the critical role of Purkinje cells in the generation and migration of granule cells, the heterogeneous distribution of cellular effects induced by ectopic En expression suggests a relatively late morphogenetic role for this and other segment polarity proteins, mainly oriented at lobule junctions.

Key words: Purkinje cell; granule cell; cerebellum; compartment; engrailed; wnt
The cerebellum occupies a unique position with respect to rostrocaudal patterning in the mammalian brain. It arises from the midhindbrain junction, a region uniquely defined by its selective deletion in null mutants of the en-1 and wnt- 1 genes (McMahon and Bradley, 1990; Wurst et al., 1994), mouse homologs of the Drosophila en and wg segment polarity genes, respectively. This genetic dependence, coupled with the cell-selective expression of other Wnt pathway and En genes throughout its development and in adulthood (Davis and Joyner, 1988; Salinas et al., 1994; Sussman et al., 1994), suggests that the cerebellum is an ideal system in which to unravel the molecular genetic principles of nervous system patterning.

The mature cerebellum itself is subdivided by multiple anatomical and molecular boundaries into compartments arranged along both the rostrocaudal and mediolateral axes (Ross et al., 1990; Oberdick et al., 1993). A strong genetic component to the formation of these compartments is implied (Oberdick et al., 1993; Baader et al., 1996; for review, see Herrup and Kuemerle, 1997). In this context, the conserved nature of En and Wnt

Received May 30, 1997; revised Dec. 2, 1997; accepted Dec. 15, 1997.

This work was supported by National Science Foundation Grant IBN-9309611 and National Institutes of Health Grant 1RO1NS33114 to J.O.; additional support was by the Deutsche Forschungsgemeinschaft Research Stipend Ba 1483/2-1 to S.L.B. We are grateful to Dr. Alex Joyner for providing $\alpha$ Enhb- 1 antibodies. We also thank Wendy Russo and Linda Eastman for excellent animal care and Stephanie Kessinger for assistance in cell counts and analysis.

S.L.B. and S.S. contributed equally to this work.

Correspondence should be addressed to Dr. John Oberdick, Department of Cell Biology, Neurobiology, and Anatomy/Neuroscience Division, The Ohio State University, 190 Rightmire Hall, 1060 Carmack Road, Columbus, OH 43210.

Copyright (C) 1998 Society for Neuroscience $0270-6474 / 98 / 181763-11 \$ 05.00 / 0$ signaling from flies to mice (Danielian and McMahon, 1996) suggests a critical role for these gene families.

In the cerebellum, the best-studied segmentation genes are the homeobox protein-encoding genes en-1 and en-2. Although a null mutation in mice of the en-1 gene results in a deletion of the cerebellar primordium starting at approximately embryonic day 9 (E9) (Wurst et al., 1994), elimination of the en-2 gene has relatively subtle effects on cerebellar development (Millen et al., 1994). Specifically, En-2 null mice show significant cell loss resulting in a decreased cerebellar size as well as subtle effects both on patterns of cerebellar foliation (Millen et al., 1994) and sagittally oriented bands (Kuemerle et al., 1997). The subtlety of these effects implies either a limited role for En genes with respect to cerebellar patterning or, more likely, that the totality of this role is difficult to reveal by genetic knock-out because of the very early role of, and compensation of the En-2 null mutant phenotype by, En-1.

To analyze further the role of the En genes in cerebellar patterning with particular attention to rostrocaudal versus mediolateral effects, we took a gain-of-function approach. By ectopically expressing a gene in cells that normally do not express it, this method can suggest potential functions of the gene in normal sites of expression (Lewis, 1978; McGinnis and Krumlauf, 1992). En-2 was chosen for these studies because of its predominant expression over En-1 both during the late embryonic period and during the postnatal phase when En-1 is no longer expressed and En-2 is restricted to granule cells (Davis and Joyner, 1988). The promoter of the Purkinje cell-specific gene pcp-2(L7) (Oberdick et al., 1990; Vandaele et al., 1991) was chosen for the overexpression of En-2. This gene and its transgene derivatives have been shown to begin expression at approximately E15 in a distinct sagittally oriented 
subset of Purkinje cells (Oberdick et al., 1993). By adulthood, however, all Purkinje cells express L7 and L7-based transgenes.

En-2 has also been shown to be expressed in a pattern of sagittally organized stripes during the late embryonic period, and this pattern was suggested to be complementary to that of L7 (Millen et al., 1995). Therefore, expression of En-2 driven by the pcp-2(L7) gene promoter would be expected to be ectopic with respect to zonal patterning during late embryogenesis and with respect to cell type postnatally. Because the patterning event critical for establishment of the cerebellar sagittal banding pattern has been demonstrated to occur before E14.5 in mice (Oberdick et al., 1993), no major perturbations in sagittal banding would be predicted in this transgenic model. As demonstrated here, this prediction has been borne out. In contrast, significant selective effects were observed in fissures that divide the cerebellum into lobules. Overall, a deterministic mechanism of fissurization and lobulation is supported, controlled at least in part by an En-sensitive property of Purkinje cells.

\section{MATERIALS AND METHODS}

Construction of L7En-2 transgenic lines. To clone the En-2 coding region, we used the following primers in reverse transcription (RT)-PCR from total RNA prepared from postnatal day 8 (P8) cerebellum: En-2-5' 5'-AGGCGATTTGGGATCCTCTGTGAAGTATGGAGGAG-3'; En-2-3' . . 5' ACCGCCCTGGGATCCCTACTCGCTGTCCGACTTGC-3'.

Primer sequences were based on the full-length En-2 cDNA sequence found in GenBank (accession number L12705). BamHI sites were mutated into the otherwise perfect match of these primers to the En-2 cDNA sequence. The PCR reaction product was then digested with Bam $\mathrm{HI}$ and cloned into the unique BamHI site of the Purkinje cell expression vector L7DAUG (Smeyne et al., 1995). The En-2 coding region insert was then sequenced on both strands using successive primers. The L7En-2 gene construct was released from the vector backbone by digestion with HindIII and EcoRI, and the fragment was gel purified and eluted (GeneClean; BIO 101, La Jolla, CA). Transgenic mice were then made by standard pronuclear injection as reported previously (Oberdick et al., 1990).

All of the observations presented here were prepared from transgenic line 20 in an FVB/N background (Taconic, Germantown, NY), except for the $\beta$-galactosidase ( $\beta$-gal) whole mounts (see Fig. 4 ) that were prepared from line 39 in a B6C3F1 hybrid background (Jackson Labs). Measurements of cerebellar size effects were made in adult animals from four separate lines $(20,33,39$, and 40$)$. All showed a similar decrease in size relative to wild type.

Histochemistry and immunohistochemistry. Before brain dissection, animals were perfused transcardially with $4 \% p$-formaldehyde in PBS after anesthetization with Avertin. Brains were then dissected and cryoprotected in $23 \%(\mathrm{w} / \mathrm{v})$ sucrose in PBS before mounting in OCT (TissueTek) and sectioning on a cryostat. Brains were generally cut in the sagittal plane (L7 and En-2 immunochemistry) at $40 \mu \mathrm{m} / \mathrm{section}$, and sections were generally removed from the knife and placed immediately into PBS in a microtiter plate (for immunohistochemistry) or directly onto slides for cresyl violet and methyl green staining.

The following dilutions of antiserum were used: L7Pep1 (Oberdick et al., 1988), 1:1000; En-2 ( $\alpha$ Enhb-1) (courtesy of Dr. Alex Joyner; Davis et al., 1991), 1:1000. In all cases, sections were reacted free-floating in wells, and primary antibody binding was revealed using the Vectastain ABC kit according to the instructions of the manufacturer (Vector Laboratories, Burlingame, CA).

In situ hybridization. Riboprobe synthesis, preparation of sections, and hybridization were performed as reported previously (Bian et al., 1996). A 218 bp Bam HI-ClaI fragment (corresponding to the N-terminal portion of En-2) of the full coding sequence fragment that was used to make the L7En-2 construct was subcloned into pBluescript; this clone was linearized with Bam HI, and antisense riboprobe was synthesized with $\mathrm{T} 7$ polymerase. This probe would detect both endogenous En-2 and transgene L7En-2 mRNAs. L7 probe is the same as that described previously (Bian et al., 1996) and should also detect both endogenous L7 and transgene L7En-2 mRNAs, except the former is much more abundant than the latter. The following 30 base oligonucleotide was used to detect specifically the transgene-encoded mRNA: 5'-ACT TCA CAG AGG ATC CTG AGG GGT GAG CAG-3'. This corresponds to the junction between L7 and En-2 sequences. This oligonucleotide was labeled as reported previously using terminal transferase (Bian et al., 1996), and hybridization was performed overnight at $37^{\circ} \mathrm{C}$, followed by standard washes in which the final wash was performed in $0.5 \times \mathrm{SSC}$ at $63^{\circ} \mathrm{C}$. These conditions were determined empirically by performance of a melting curve.

Northern and Western blots. Northern blots were performed as reported previously (Bian et al., 1996). Western blots were performed as reported previously (Bian et al., 1996) using HRP-based immunodetection (Vector Laboratories) followed by visualization using a chemiluminescent substrate (Renaissance; NEN). L7 antibody was used at a dilution of 1:1000; $\alpha$ Enhb-1 was used at 1:250.

$R T-P C R$. Embryonic animals were obtained from pregnant females that were positively identified by vaginal plug (morning of plug, day 0.5 ). The age was further confirmed by determining the stage of fore- and hindlimb development before brain dissection (Rugh, 1993). The whole brains of 13- and 14.5-d-old embryos were prepared and cut in the embryonic mesencephalic flexure. The caudal part containing the cerebellar primordium and brainstem down to the cervical flexure was collected and used for RT-PCR (unfused left and right halves were pooled). At all later time points, cerebella could be isolated from the rest of the brain. After RNA preparation, reverse transcription of $2 \mu \mathrm{g}$ of RNA was performed, followed by PCR using the following primer pairs: L7En-2-specific, 5'-AAG AAT TCT AGG TAC TAG GAT TTA GGG GCA CTT CTG AG and 3'-AGT TGG TGA TGC GAT GTG GAT GCT C; L7-specific, 5' - . . (same as L7En-2-specific) and 3'-ACA AGC TTA CTA GTG CCA AGT GTT TTA TTG TTT; En-2-specific, 5'TGG ATG GAG TGC TCA AAG CC and 3'-TTG CAT TGT TTC GCG CGG CCC TAG ACA TGC.

PCR reactions were performed at standard conditions using 35 cycles of $94^{\circ} \mathrm{C}$ for $45 \mathrm{sec}, 63^{\circ} \mathrm{C}$ for $1 \mathrm{~min}$, and $72^{\circ} \mathrm{C}$ for $2 \mathrm{~min}$.

Tissue measurements and cell counts. Cresyl violet-stained sagittal sections of two P9 and adult wild-type and two P9 and adult L7En-2 transgenic mice were prepared. Every 10th $12-\mu \mathrm{m}$-thick section was evaluated by counting the number of Purkinje cells. Purkinje cell counts reported in Table 1 are from one wild-type and transgenic pair/time point, but the data were confirmed in a second pair. In addition, the percent difference in Purkinje cell number was confirmed using counts derived from L7- and calbindin-immunostained sections (40 $\mu \mathrm{m}$ thick).

Measurement of the whole cerebellar area was performed using IPLab Spectrum (Signal Analytics Corp.) to analyze digitized video images of methyl green-stained sagittal sections. Generally, every third section was measured. The vermis includes all sections showing lobules I/II-X. All other sections, starting from a point where lobule I/II disappears and ending where no middle cerebellar peduncle is observable, are summarized in the lateral region. The number of sections evaluated was three for each region and time point. Values were confirmed by measurements in at least one more animal (the total number of wild-type and transgenic mouse pairs analyzed was two for P0, two for P9, and three for adults).

For measuring the relative decrease in fissure depth, methyl greenstained sections of cerebellum from P7 animals were analyzed using IPLab Spectrum. The circumference of the cerebellum was defined by a line drawn around the surface of the cerebellum excluding the fissures. The depth of the fissures was defined from the base of the fissure to a point where the molecular layer of two neighboring lobules separated. Vermis and hemispheres were as defined for area measurements. Data in Table 2 are from one wild-type and one transgenic animal from line 20. Similar differences were observed in other lines and at other time points.

For quantitation of the external germinal layer (EGL) thickness, the entire circumference (including fissures) of transgenic and wild-type sections was divided into an equal number of segments. At the midpoint of each segment, a radial line was drawn from just beneath the pia to the deep limit of the EGL. The length of this line was measured by IPLab Spectrum software and then plotted against position in the cerebellum. Vermis and hemispheres were as defined above. Generally, the wild-type and transgenic curves were found to intersect at lobule surfaces but to diverge significantly within fissures.

\section{RESULTS}

\section{L7En-2 transgenic mouse construction} and characterization

The coding region of En-2 was isolated by RT-PCR from P8 cerebellar RNA. This cDNA fragment encompassed only the 989 
Table 1. Decrease in Purkinje cell number and area in cerebellum of L7En-2 versus wild-type mice

\begin{tabular}{|c|c|c|c|c|c|c|}
\hline & \multicolumn{3}{|l|}{ Vermis } & \multicolumn{3}{|c|}{ Hemisphere } \\
\hline & $\mathrm{P} 0$ & P9 & Adult & $\mathrm{P} 0$ & P9 & Adult \\
\hline \multicolumn{7}{|l|}{ Wild type } \\
\hline PC number & $\mathrm{ND}$ & $610 \pm 60$ & $700 \pm 60$ & ND & $420 \pm 10$ & $380 \pm 20$ \\
\hline Area $\left(\mathrm{mm}^{2}\right)$ & $1.1 \pm 0.1$ & $4.4 \pm 0.2$ & $8.8 \pm 0.4$ & $0.8 \pm 0.2$ & $3.3 \pm 0.3$ & $6.3 \pm 0.6$ \\
\hline \multicolumn{7}{|l|}{ L7En-2 } \\
\hline PC number & $\mathrm{ND}$ & $410 \pm 40$ & $410 \pm 90$ & ND & $280 \pm 40$ & $220 \pm 20$ \\
\hline Area $\left(\mathrm{mm}^{2}\right)$ & $0.7 \pm 0.2$ & $2.8 \pm 0.1$ & $4.3 \pm 0.2$ & $0.7 \pm 0.1$ & $2.4 \pm 0.3$ & $3.6 \pm 0.4$ \\
\hline \multicolumn{7}{|l|}{ Decrease $(\%)$} \\
\hline PC number & ND & $33 \pm 13$ & $41 \pm 9$ & ND & $32 \pm 8$ & $40 \pm 7$ \\
\hline Area $\left(\mathrm{mm}^{2}\right)$ & $36 \pm 19$ & $36 \pm 4$ & $51 \pm 5$ & $13 \pm 20$ & $27 \pm 11$ & $43 \pm 10$ \\
\hline
\end{tabular}

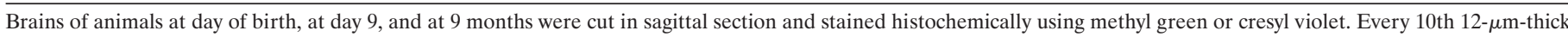

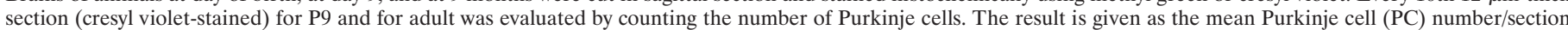

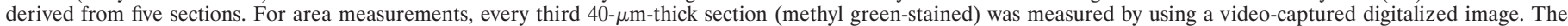

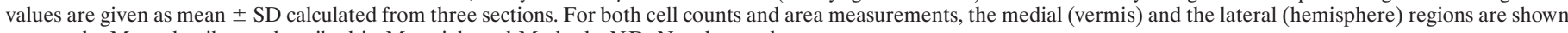
separately. More details are described in Materials and Methods. ND, Not detected.

Table 2. Comparison of the decrease in fissure depth with the decrease in circumference of L7En-2 versus wild-type cerebellum

Fissure depth $(\mu \mathrm{m})$

\begin{tabular}{|c|c|c|c|c|c|c|c|c|}
\hline \multirow[b]{2}{*}{ Vermis } & \multicolumn{7}{|c|}{ (2) } & \multirow{2}{*}{$\begin{array}{l}\text { Circumference } \\
(\mathrm{mm})\end{array}$} \\
\hline & I/II-III & III-IV & V-VI & VI-VII & VII-VIII & VIII-IX & $I X-X$ & \\
\hline Wild type & $580 \pm 310$ & $1340 \pm 580$ & $1960 \pm 350$ & $310 \pm 80$ & $680 \pm 60$ & $1130 \pm 210$ & $800 \pm 110$ & $8.86 \pm 1.13$ \\
\hline L7En-2 & $450 \pm 240$ & $820 \pm 290$ & $1100 \pm 130$ & $100 \pm 40$ & $400 \pm 80$ & $740 \pm 130$ & $520 \pm 130$ & $6.96 \pm 1.01$ \\
\hline Decrease $(\%)$ & $34 \pm 19$ & $35 \pm 11$ & $43 \pm 9$ & $73 \pm 11$ & $39 \pm 12$ & $39 \pm 10$ & $35 \pm 14$ & $29 \pm 1$ \\
\hline \multirow[t]{2}{*}{ Significance } & - & + & + & + & + & + & - & \\
\hline & \multicolumn{7}{|c|}{ Fissure depth $(\mu \mathrm{m})$} & \multirow{2}{*}{$\begin{array}{l}\text { Circumference } \\
(\mathrm{mm})\end{array}$} \\
\hline Hemisphere & & & $\operatorname{PrF}$ & PsF & $\mathrm{IcF}$ & ApmF & PfF & \\
\hline Wild type & & & $1060 \pm 330$ & $750 \pm 220$ & $940 \pm 290$ & $450 \pm 90$ & $890 \pm 200$ & $6.76 \pm 0.52$ \\
\hline L7En-2 & & & $700 \pm 150$ & $460 \pm 140$ & $750 \pm 240$ & $230 \pm 80$ & $620 \pm 200$ & $5.91 \pm 0.40$ \\
\hline Decrease $(\%)$ & & & $27 \pm 14$ & $36 \pm 16$ & $29 \pm 6$ & $50 \pm 14$ & $31 \pm 13$ & $13 \pm 3$ \\
\hline Significance & & & - & + & + & + & + & \\
\hline
\end{tabular}

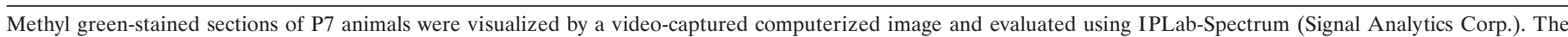

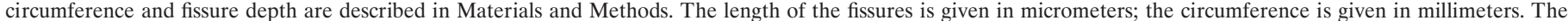

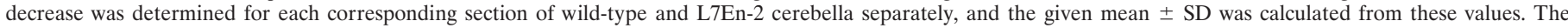

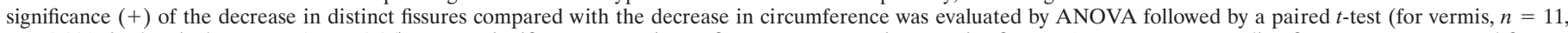

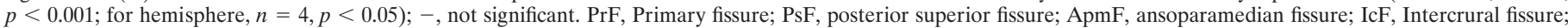
$\mathrm{PfF}$, parafloccular fissure.

bp region spanning from the start to the stop codon (positions 31-1020 of En-2 cDNA sequence; GenBank accession number L12705) (Logan et al., 1992). This fragment was cloned into the unique $B a m \mathrm{HI}$ site of the $\mathrm{L} 7 \Delta \mathrm{AUG}$ promoter vector (Smeyne et al., 1995), and the L7En-2 construct (Fig. 1A) was injected into fertilized mouse eggs using standard procedures (Oberdick et al., 1990). The construct was made without epitope tagging to avoid unpredictable effects on fidelity of transgene expression and on encoded protein (En-2) function. Six independent transgenic mouse lines were obtained, two of which showed no detectable expression in the cerebellum by Northern blot analysis. In contrast, animals from the other four lines showed a subtle gait defect characterized more as a loss of movement fluidity rather than as a true ataxia, and each of these showed a clearly detectable transgene mRNA band of the appropriate size on a Northern blot (Fig. 1B). Western blot analysis using antibodies for L7 or En-2 revealed proteins only of native size in adult cerebellum (Fig. $1 C)$; fusion proteins were not expected because the L7DAUG vector was constructed by the mutation of all possible ATG codons in all L7 exons (Smeyne et al., 1995; see Fig. $1 A$ ). No detectable increase in En-2 protein levels in the adult is observ- able by Western blot in contrast with what might have been expected by additional expression in Purkinje cells; this may be because of the compensatory effect of slight downregulation of endogenous En-2 mRNA levels in the transgenic mice (Fig. 1B).

Using a riboprobe for En-2, we have shown transgene expression in Purkinje cells to be superimposed on the pattern of endogenous En-2 mRNA by in situ hybridization (Fig. $2 A-D$ ). Likewise, by immunocytochemistry, expression of En-2 protein in the nuclei of Purkinje cells is shown to be superimposed on the pattern of endogenous En-2 expression (primarily in granule cells) during the early postnatal period (Fig. $2 E, F$; see also Fig. $6 F$ ).

\section{Developmental expression of the L7En-2 transgene}

To interpret the phenotype of L7En-2 mice, it was important to determine the time course of transgene expression. To do this, RT-PCR was performed at high cycle number using RNA prepared from cerebellar tissue spanning the time frame from E13 to adult (Fig. 3A). Endogenous En-2 mRNA could be easily detected at all ages. L7En-2 transgene expression was undetectable at E13 and E14.5 but was easily detectable at P0 and in adults only in the transgenic mice. The same was generally true of endogenous L7 

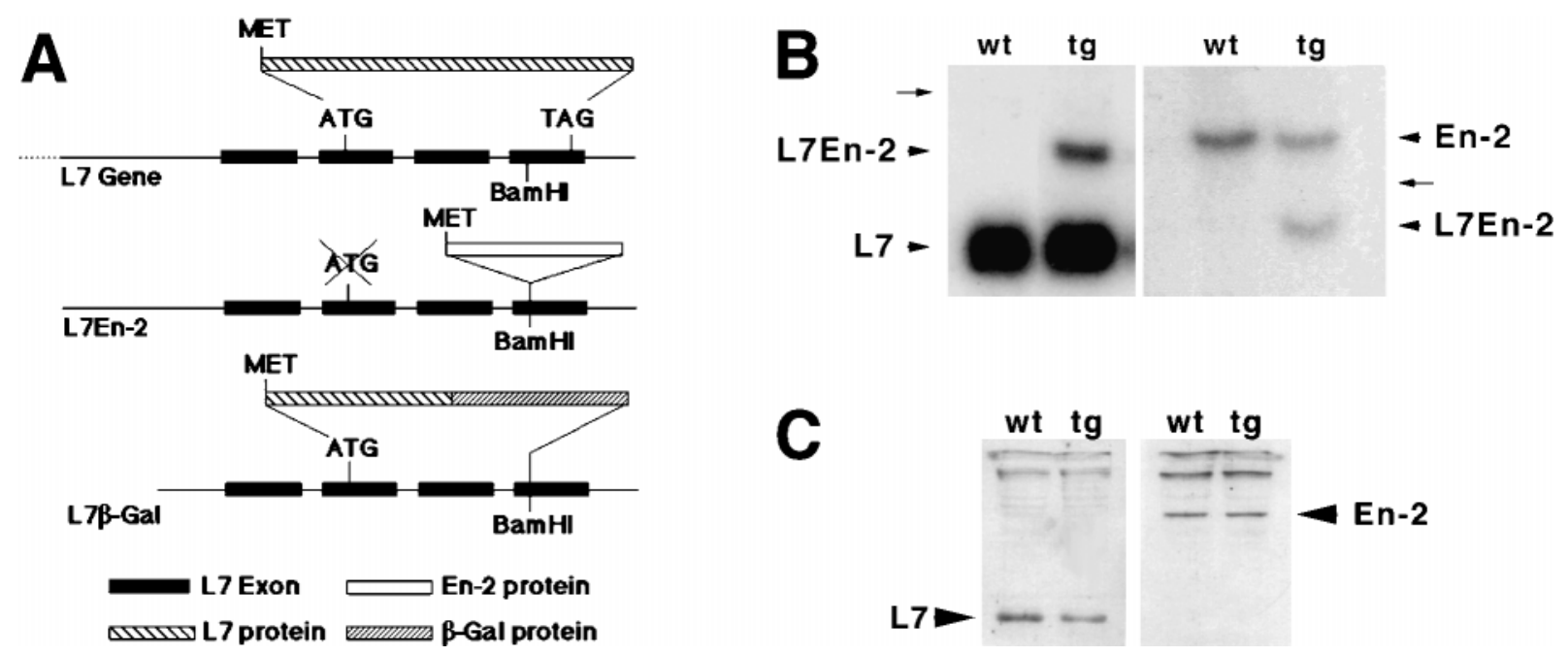

Figure 1. Construction and characterization of L7En-2 transgenic mice. A, Gene structure of the endogenous L7 gene (top), the L7En-2 transgene (middle), and the L7 $\beta$-Gal construct (bottom). The promoter of the L7En- 2 transgene is $\sim 1 \mathrm{~kb}$; that of L7 $\beta$-Gal (corresponding to L7 $\beta$ G3 that expresses bands in both a precocious and prolonged manner; Oberdick et al., 1993) is $\sim 0.5 \mathrm{~kb}$. Translation of the L7En- 2 transgene construct can only initiate within the En-2 coding region because all possible start ATGs were removed from the L7 exons to form the L7DAUG base vector (Smeyne et al., 1995). Animals carrying the L7 $\beta$-Gal construct were crossed into L7En-2 mice to test the effect of En-2 on sagittal banding (see Fig. 4). $B$, Northern blot analysis to detect L7En-2 transgene expression. The panel on the left was probed with L7 cDNA and that on the right with En-2 (using the same fragment used for in situ hybridization; see Materials and Methods). Although from the same gel, the two panels represent different size ranges (note arrows denoting positions of 18S RNA). In both panels, L7En-2 refers to the mRNA encoded by the transgene. Note that the level of transgene mRNA is significantly lower than is that of endogenous L7 (left) but is equal to the level of endogenous En-2 (right). wt, Ten micrograms of wild-type cerebellar RNA; tg, $10 \mu \mathrm{g}$ of transgenic cerebellar RNA. C, Detection of correct L7 and En-2 protein species in L7En-2 transgenic cerebellum by Western blot. No aberrant-sized proteins were detected with either L7 or En-2 antibodies as might result from unexpected frameshifts or L7-En-2 protein fusions. wt, Twenty micrograms of wild-type cerebellar protein; $t g, 20 \mu \mathrm{g}$ of L7En-2 cerebellar protein.

mRNA in wild-type mice, although the latter was very weakly detectable at E14.5. Thus, although we cannot rule out extremely low levels of transgene expression at these early time points, it is most likely activated after E14.5 (but before E17.5; see Fig. $3 B-D)$.

Although riboprobe to the coding region of En-2 would be expected to hybridize to both the endogenous En-2 mRNA and that encoded by the transgene, the patterns of expression of these two species in E17.5 cerebellum could be easily resolved by in situ hybridization using this probe (Fig. $3 B$ ). Endogenous En-2 expression typically extended from the region around the deep cerebellar nuclei up to the cortex, where it was distributed throughout the depth of the cortex. Although endogenous En-2 expression was rather diff use, in favorable sections discrete clusters of increased En-2 expression were revealed in the wild-type cerebellar cortex (Fig. 3B, left, arrowheads). The pattern of these clusters in the wild type was similar to the pattern reported previously for En-2 (Millen et al., 1995) and was approximately the complement of the $\mathrm{L} 7$ pattern (compare Fig. $3 B$, left, with $C$, left). As might be expected, therefore, the pattern of En-2 expression was much more uniform in the cerebellar cortex of the transgenic mice (compare Fig. $3 B$, left, with $B$, right), being composed of the combined patterns of endogenous and transgene En-2. In fact, the additional En-2 signal attributed to transgene expression describes a recognizable L7-like pattern (compare Fig. $3 B$, right, with $C$, right).

The pattern of L7 expression was nearly equivalent in the wild type versus transgenic (compare Fig. 3C, left, with $C$, right), appearing negative at the midline with the highest expression slightly more lateral. This bilaterally symmetric zone of highest expression consisted of two closely spaced clusters separated by a thin gap. More lateral was a broader negative zone (Fig. 3C, arrowheads) followed by a another zone of expression. The major difference between the wild-type and transgenic L7 patterns was a decrease in the size of the midline zone of negative expression in the transgenic; the amount of this decrease varied from no discernible difference between wild type and transgenic to that shown in Figure $3 C$, depending on cerebellar position.

Using an oligonucleotide probe specific for the junction of L7 and En-2 sequences within the L7En-2 construct (see Materials and Methods), we determined in situ hybridization conditions under which expression of the transgene but not the endogenous L7 or En-2 genes could be detected (Fig. 3D). No signal was detectable in wild-type cerebellum (Fig. 3D, left). In contrast, the pattern of signal in transgenic cerebellum was nearly identical to that produced by $\mathrm{L} 7$ probe in adjacent sections (compare Fig. $3 D$, middle, with $D$, right; sections are more caudal than are those in $B$ and $C$ ). These data confirm the near equivalence of transgene and L7 gene expression patterns, as suggested by use of the En-2 riboprobe above.

\section{Reduction in size and loss of Purkinje cells in adult cerebellum}

In whole mount, the cerebellum can be seen to be grossly smaller in L7En-2 mice as compared with wild type (Fig. 4). In adult sagittal sections near the midline, this is seen to be mainly an effect on the radial size of the cerebellum in both the rostrocaudal and dorsoventral directions (see Fig. 2A,B). To quantitate these effects, we calculated the cerebellar area for evenly spaced sections from the midline to lateral hemisphere in adults (line 20). Because the mediolateral distance did not differ significantly between wild-type and transgenic cerebella, the same number of sections were collected and analyzed from brains of each type. The reduction in area in L7En-2 relative 

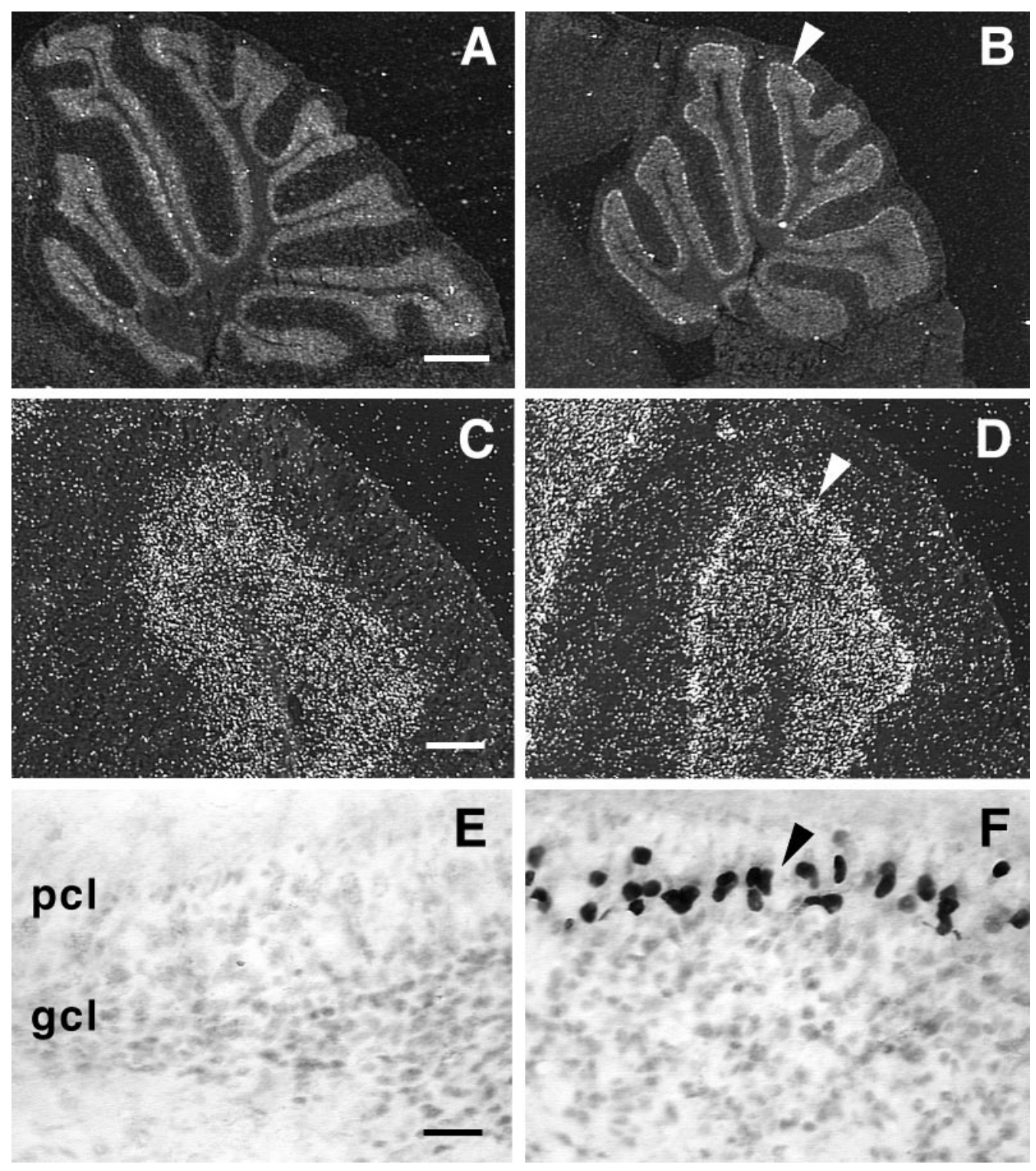

Figure 2. Detection of transgene expression in Purkinje cells by in situ hybridization and immunocytochemistry. $A-D$, In situ hybridization with a 218 bp ${ }^{35} \mathrm{~S}$-labeled antisense riboprobe corresponding to the N-terminal portion of the En-2 coding region is shown. En-2 expression in the wild type is restricted to the granule cell layer $(A, C)$. In L7En-2 transgenics, En-2 is detected in granule cells and Purkinje cells $(\operatorname{arrowheads}$ in $B, D)$. $E, F$, En-2 protein is restricted to granule cells in P3-P4 wild-type cerebellum $(E)$ but is additionally expressed in Purkinje cell nuclei (arrowhead) in L7En-2 transgenics $(F)$. pcl, Purkinje cell layer; gcl, granule cell layer. Scale bars: $A, B, 500 \mu \mathrm{m} ; C, D, 100 \mu \mathrm{m} ; E, F, 50 \mu \mathrm{m}$.

to wild-type cerebellar sections did not differ significantly from vermis $(51 \pm 5 \%$ reduction $)$ to hemispheres $(43 \pm 10 \%$ reduction) (Table 1). Likewise, Purkinje cell numbers were determined, and the average percent decrease in L7En-2 relative to wild-type vermis $(41 \pm 9 \%)$ did not differ significantly from that in hemispheres $(40 \pm 7 \%)$. Thus, Purkinje cell loss was found to be evenly distributed across the mediolateral axis of the cerebellum and to parallel approximately the change in cerebellar volume.

It is difficult to determine the time course of Purkinje cell loss in L7En-2 cerebella. Purkinje cell counts at P9 show an $\sim 33 \%$ reduction in $\mathrm{L} 7 \mathrm{En}-2$ relative to wild type in both the vermis and hemispheres (Table 1); more counts would have to be performed to determine whether this was statistically different from the change observed in adults. Earlier than this time, however, relative counts are more difficult to establish because Purkinje cells are more difficult to identify unambiguously. Nevertheless, by $\mathrm{P} 0$, there is already a reduction by $\sim 36 \%$ of the area in near-midline vermal sections (Table 1), whereas none is detectable at E17 (data not shown). It is impossible to tell, however, to what degree this reduction at P0 is attributable to Purkinje cell loss versus effects on overall cerebellar growth. Despite this ambiguity, it is quite clear from these data that there is a major effect on cerebellar growth starting around birth and continuing throughout the early postnatal period.

\section{Analysis of L7 sagittal zones}

Based on its late embryonic pattern of expression, it has been suggested that En-2 may play a role in the establishment of sagittal banding patterns in the cerebellum (Millen et al., 1995). Because the pattern of En-2 expression driven by the L7 promoter 


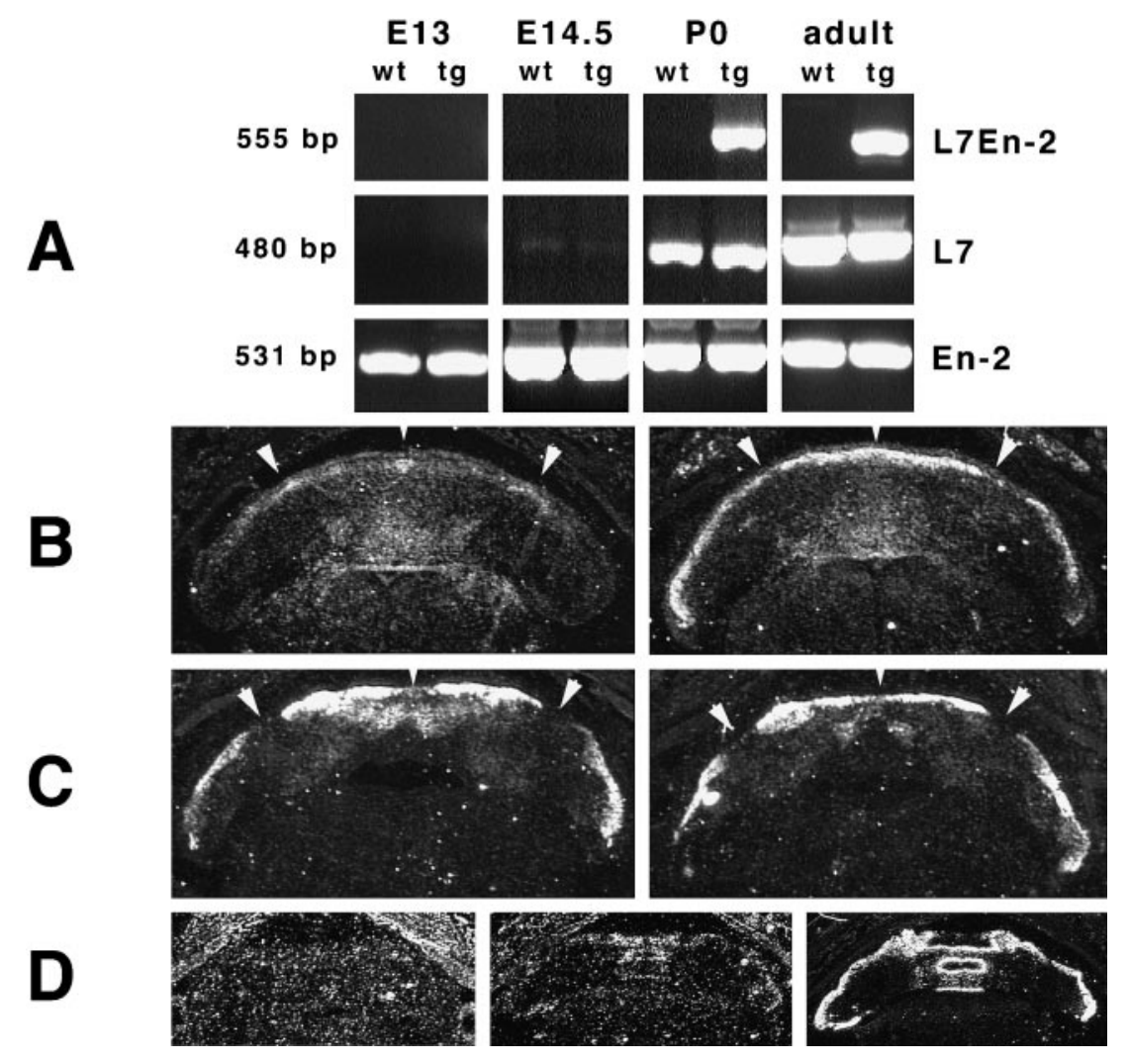

Figure 3. Embryonic and neonatal expression of L7En-2 transgene. $A$, RT-PCR was performed using RNA prepared from E13, E14.5, P0, and adult cerebellum. Primers were designed that could distinguish the L7En-2 transgene mRNA from endogenous L7 and En-2 mRNAs (see Materials and Methods). Whereas En-2 mRNA is detectable at all time points and in both transgenics $(t g)$ and wild types ( $w t)$, L7 is only very weakly detectable in both genotypes at E14.5 but is strongly detectable at $\mathrm{P} 0$ and in adults. The transgene mRNA can only be detected in P0 and adult transgenics, never in wild types. $B-D$, In situ hybridization to detect L7En-2 transgene expression is shown. Horizontal sections of E17.5 wild-type $(B, C$, left $)$ and transgenic (right) cerebellum were hybridized with En-2 probe $(B)$ or $\mathrm{L} 7$ probe $(C)$. The En-2 probe reveals a pattern of expression in the transgenic that is a superimposition of the wild-type L7 and En-2 expression patterns. Arrowheads indicate positions of endogenous En-2 clusters and L7-negative zones. An oligonucleotide probe $(D)$ sequences (see Materials and Methods) was used to compare transgene expression with endogenous L7 expression. Transgene is undetectable in wild types $(D$, left $)$ but is detectable in transgenics (middle) in a pattern identical to that of L7 in adjacent sections (right). was ectopic with respect to the wild-type En-2 pattern (Fig. 3), the effect on a sagittally oriented molecular banding pattern was investigated in adult transgenic mice. To this end, a line of mice carrying a truncated version of the L7 promoter fused to the coding region of bacterial $\beta$-gal was crossed into the L7En-2 line. This truncated construct, called L7 $\beta$ G3 (shown as L7 $\beta$-Gal in Fig. 1 ), was shown previously to be expressed in an aberrant pattern of sagittal bands that are continuously visible in whole mount from the late embryonic period until maturity (Oberdick et al., 1993).

In an L7En- 2 mutant background, the pattern of $\beta$-gal stripes is very similar to that in a wild-type background (Fig. 4). One obvious change is the lack of appearance of weakly stained bands in the mutant. However, these "interband" regions normally activate L7 $\beta$ G3 expression slowly during development, and their absence is likely to reflect a reduced level of expression of the $\beta$-gal transgene in the mutant background (revealed by enzymatic assay of cerebellar extracts; data not shown). The only area in which a true band deletion may have occurred is at the midline of lobule IX (Fig. 4B). There are a few zones at or near the midline that are reduced in width (for example, the L7-negative zone at the midline in the rostral half of lobule VI, the first L7-positive zone lateral to the midline in lobule VIII, and the first L7-positive zone lateral to the midline in lobule IX) that may be related to the variable decrease in the width of the midline L7-negative zone observed at E17.5 (Fig. 3). In general, however, band width is unchanged in the transgenic relative to the wild type.

In contrast to the general lack of effect on the gross pattern of sagittal bands, a reduction in the anteroposterior dimension of most lobules can be seen in whole mount. Of special note, the loss of two fissures, one separating sublobules V Ia and V Ib and the other separating IXa and IXb, can be clearly seen in the rostral (Fig. 4A) and caudal (Fig. 4B) whole-mount views, respectively. The loss of the fissure in lobule VI is of particular interest because the boundary dividing VIa and VIb remains clearly evident in the form of distinct $\beta$-gal banding patterns. Because of these observations, patterns of foliation were examined more closely.

\section{Evidence of selective Purkinje cell loss in cerebellar fissures}

Despite the indeterminacy of the time course of Purkinje cell loss before P9, there is one feature that stands out in the sagittal plane that may be of relevance with respect to Purkinje cell loss. Namely, all sublobular fissures are eliminated in the L7En-2 cerebellum (Fig. 5). This phenotype affects lateral as well as medial cerebellum, because the fissure that normally bisects the simplex lobule is eliminated in the mutant in a similar manner to its medial counterpart dividing lobule VI (Fig. 5B, D, arrows). In addition to the loss of all sublobular fissures, the depth of all fissures is dramatically reduced. Most notably, at P7, the primary fissure near the midline shows a $43 \%$ decrease in depth relative to wild type, whereas the same sections show only a $29 \%$ decrease in circumference, and three other fissures in the central lobe (defined as lobules VI, VII, and VIII; Altman and Bayer, 1997) show an equivalent or greater selective effect (Table 2). Similarly, in the hemispheres, fissure depth is selectively affected relative to cerebellar circumference (Table 2). The selective effect on central lobe fissures persists into adulthood, at which time the percent decrease was observed to be $40 \%$ for fissure V-VI, $69 \%$ for fissure VI-VII, and $42 \%$ for fissure VII-VIII compared with a $29 \%$ decrease in the cerebellar circumference. Thus, the total loss of sublobular fissures and the decrement in depth of some major fissures suggest a selective loss of cells in the fissures.

Direct evidence of this selective cell loss may be difficult to observe in many fissures because, assuming the cell loss is generally an early event, replacement may occur from later migrating 
A
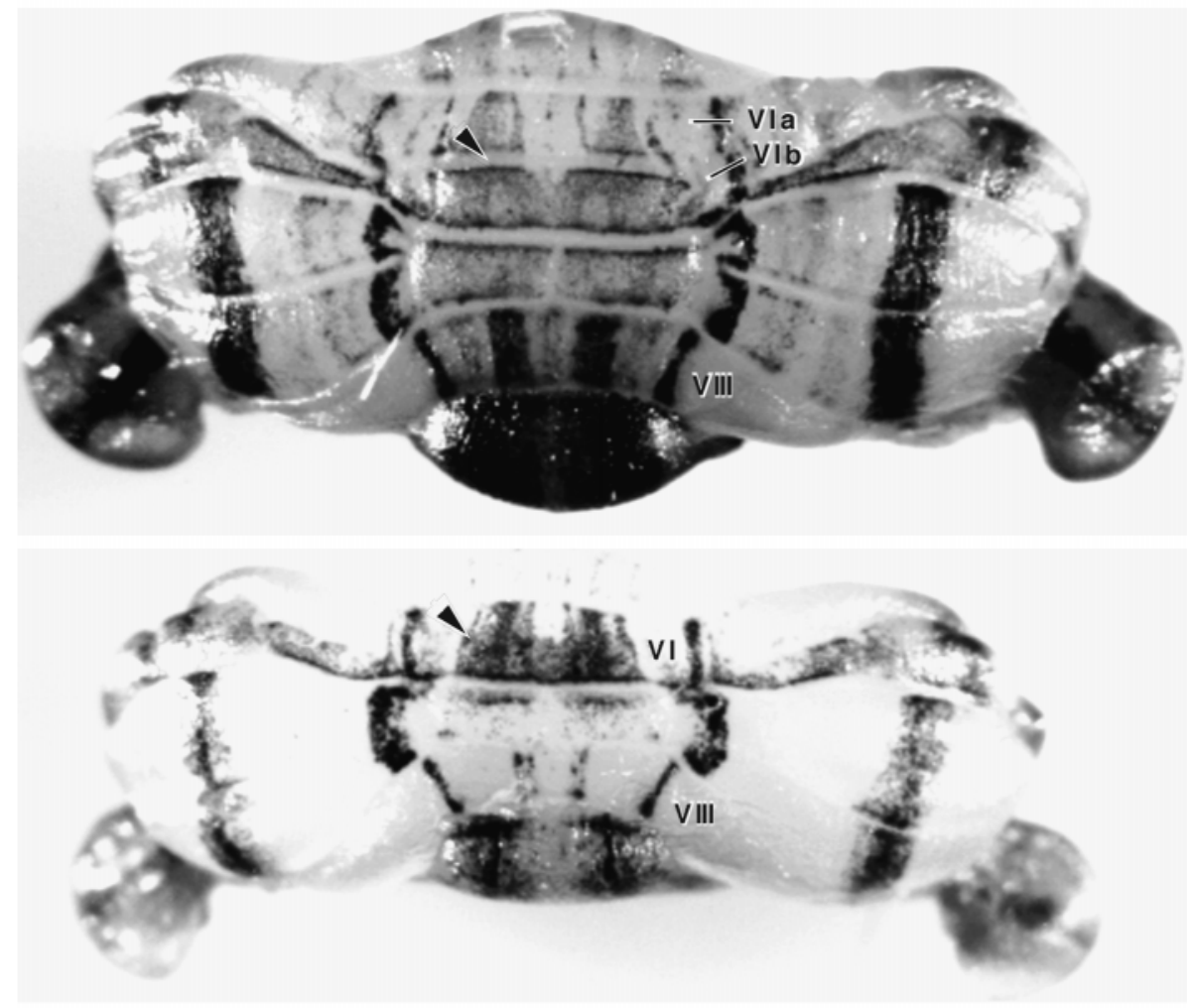

B
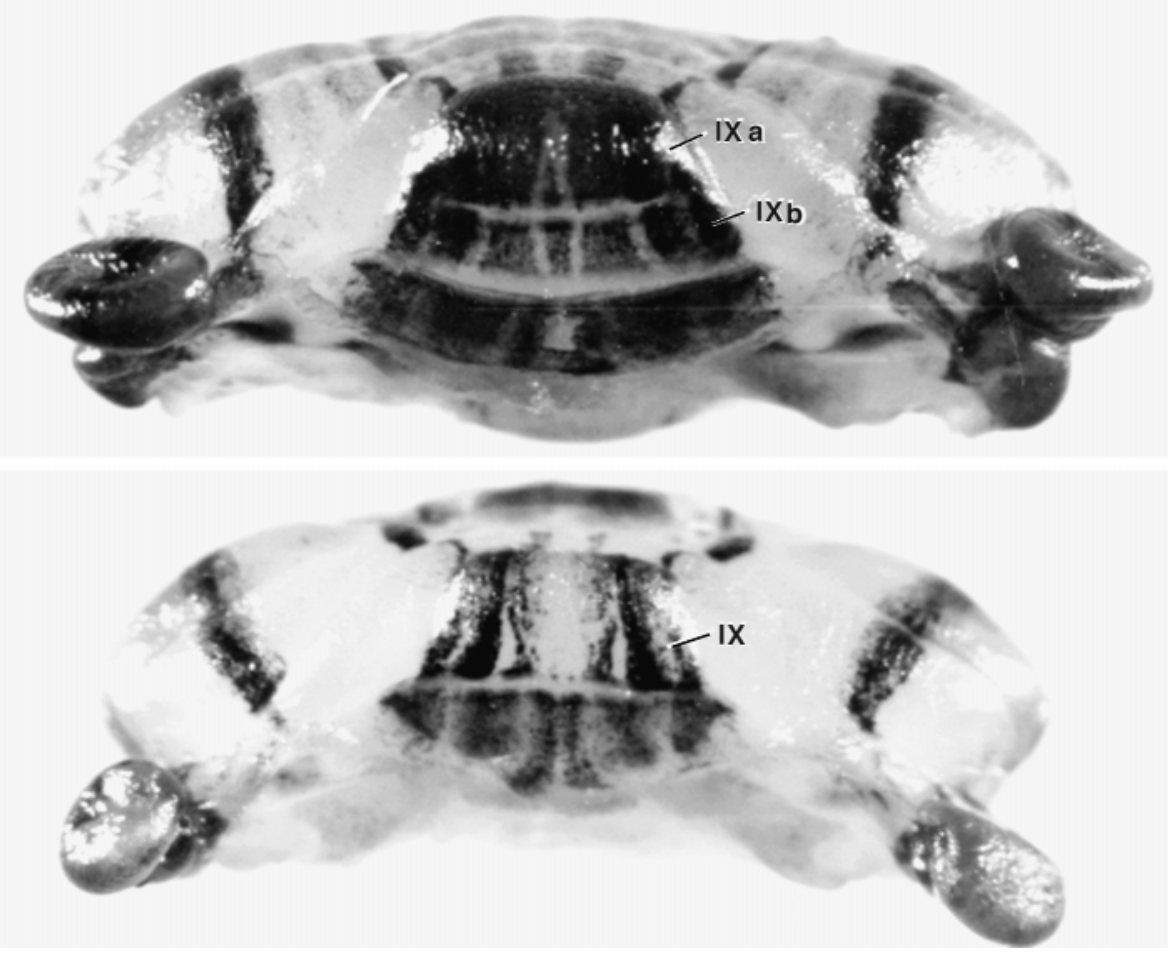

Figure 4. Analysis of L7 sagittal bands in L7En-2 transgenic mice. Animals expressing the L7 $\beta$ G3 transgene were crossed with L7En-2 mice, and the $\beta$-gal banding pattern was compared with that in a wild-type background. Images are whole-mount views of rostral $(A)$ and caudal $(B)$ cerebellar aspects at P11. In both $A$ and $B$, the wild type is at the top, and the mutant is on the bottom. The arrowhead in $A$ indicates the fissure dividing lobule $V I$ into $a$ and $b$ sublobules; this fissure is missing in the transgenics. Similarly, the fissure separating $I X a$ and $I X b$ is deleted in the transgenic $(B)$. Roman numerals identify selected lobules. and developing Purkinje cell populations. If this is true, the effect could be most pronounced in areas in which maturation normally occurs too late to be accommodated by such replacement, for example, in the central lobe. In fact, this is precisely the case. As early as P9 and continuously from P15 into adulthood, gaps can be visualized in the Purkinje cell layer within the central lobe fissures, particularly in the fissure separating lobule VII from VIII (Fig. 6D,E). Near the midline at P15, the base of lobule VII is particularly shrunken, creating the impression of a lobule in the process of "pinching off." In this area, regions devoid of Purkinje cells appear to receive compensatory dendritic branches from distant surviving Purkinje cell neighbors, which send long run- 
Figure 5. Change in lobulation pattern in L7En-2 cerebellum. $A, C$, Midline sagittal sections of wild-type $(A)$ and L7En-2 mutant $(C)$ cerebella. $B, D$, Lateral sections from the same brains shown in $A$ and $C$. All sections were stained with methyl green. Note the loss of the fissure dividing sublobules $V I a$ and $V I b$ in the mutant, shown in whole mount in Figure 4. This loss persists into the hemispheres as a loss of the fissure subdividing the lobule simplex. Arrows indicate the sublobule fissures other than that in VI that are deleted in the mutant. Scale bar, $500 \mu \mathrm{m}$. Roman numerals identify vermal lobules. Sim, Simplex lobule; $C 1$, crus I of ansiform lobule; $C 2$, crus II of ansiform lobule; $P M$, paramedian lobule.

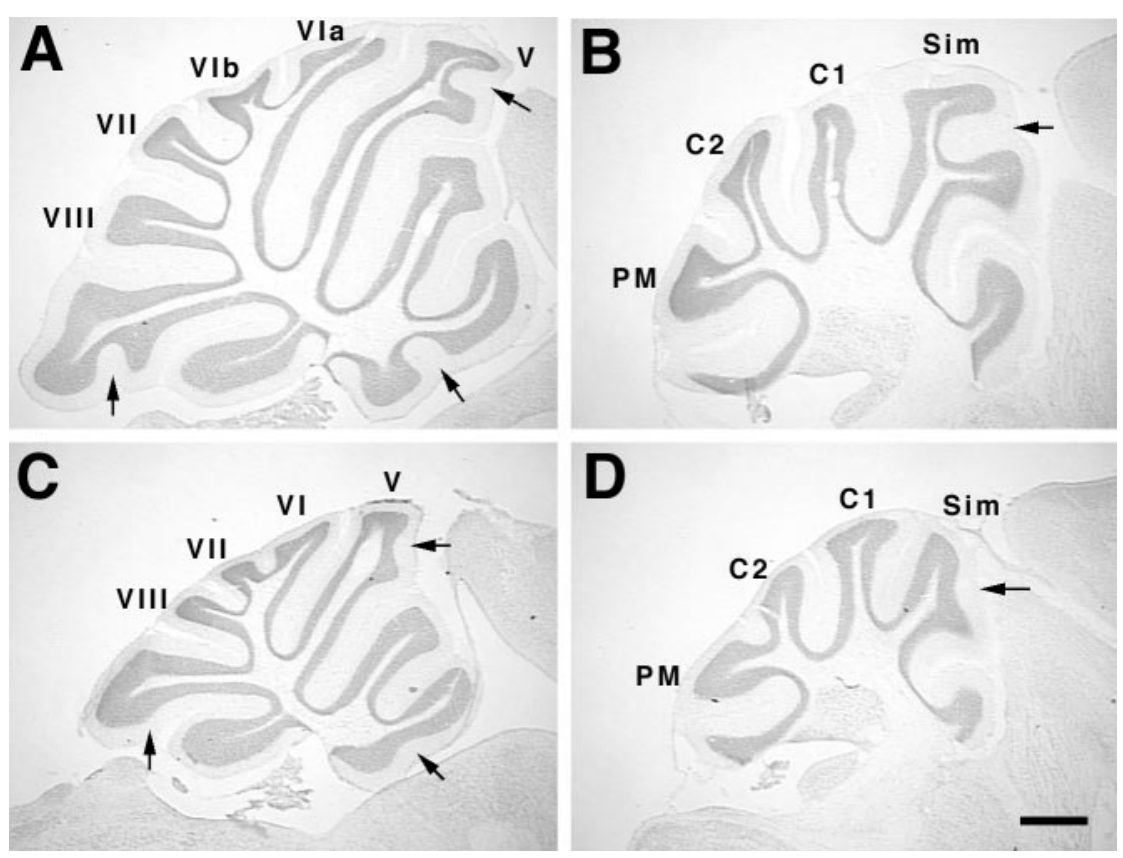

ning processes along the superficial aspect of the internal granule cell layer (IGL). Multiple radially oriented branches emanate from this process and ascend toward the cerebellar surface (Fig. $6 C)$. The gaps typically appear on one wall or the other making up the fissure, extending for variable distances along the length of the fissure, giving a distinct "patchy" appearance from section to section.

An early postnatal harbinger of these effects may be the appearance of stunted Purkinje cell dendrites at P7. This effect is localized along most of the length of the fissure wall but seems most severe toward the fissure base (Fig. 6A,B); the effect is also more widespread than is the appearance of gaps. Several days later, dendrites may be visualized in certain fissures (primarily in the central lobe) to run for long distances in aberrant tangential directions (Fig. 6C). The fissure-restricted nature of the stunted dendrites at P7 is not caused by differential expression of the transgene at this time because transgene-encoded En-2 protein is uniformly expressed at this time in all Purkinje cells (Fig. 6F). Because the stunting of Purkinje cell dendrites is more widespread than is the appearance of gaps and is therefore transient in most regions, it may be linked to an additional transient effect that was observed in the EGL.

\section{Retarded EGL development in the cerebellar deep fissures}

Despite the Purkinje cell loss in the L7En-2 transgenic mutant, many of these cells survive. The organization of the various cerebellar laminae is strikingly unchanged (Fig. 5), and except in certain restricted regions (such as in lobules VII and VIII, see Fig. 6), Purkinje cells appear morphologically normal. Among the cerebellar cells that survive, however, there are some additional transient effects that are apparent during the early postnatal period. In the period between P5 and P7, for example, there is both a delay in the growth of Purkinje cell dendrites in the cerebellar fissures (see Fig. 6) and in the formation of the EGL in these regions (Fig. 7). These effects are broadly observable in most fissures but are particularly evident in the primary fissure and other fissures within the central lobe. In addition to the decreased thickness of the EGL in fissures, the base of each fissure is characterized by a loss of fusion of the two sides of the EGL (Fig. 7B, arrows). These effects have been carefully quantitated and shown to be distributed across the entire mediolateral dimension of the cerebellum (Fig. $7 C, D$ ). Like the stunted Purkinje cell dendrites, these effects seem to be a differential responsiveness of cells in fissures to expression of En-2.

\section{DISCUSSION}

Persistent expression of En-2 in cerebellar Purkinje cells from the late embryonic stage into adulthood results in an $\sim 40 \%$ decrease in the number of Purkinje cells. This loss appears to be distributed uniformly across the mediolateral axis. In contrast to the minimal effect on sagittal banding, cerebellar cells residing within the fissures appear most sensitive to the effects of persistent En-2 expression. The latter sensitivity includes but is not restricted to effects on Purkinje cell numbers and is shown to extend to complex cellular interactions such as those required for the formation of the EGL.

\section{Purkinje cell loss}

The Purkinje cells that survive in L7En-2 mice are for the most part biochemically and anatomically normal and are arranged in appropriate laminae. Thus, many Purkinje cells seem impervious to persistent expression of En-2. To interpret the significance of this observation, it will be most important to determine the precise cause of cell loss in these animals. As a start toward this end, transgene expression is found to be undetectable in the cerebellum at E13 and E14.5 but is clearly activated shortly thereafter. It is unlikely, therefore, that the effects reported here are related to Purkinje cell generation, which is normally completed by E13 in mice (Miale and Sidman, 1961). Furthermore, to date there is no evidence at any time point (from late embryogenesis to adulthood) of discernible cell death in L7En-2 cerebella in excess of that seen in wild-type control mice, as revealed by quantitation of pyknotic figures (data to be reported elsewhere). Although cell death cannot be ruled out at this time, the data are most consistent with the failure of a subset of Purkinje cells, particularly those residing within fissures, to properly differentiate. What the fate of this subset might be is unknown. 

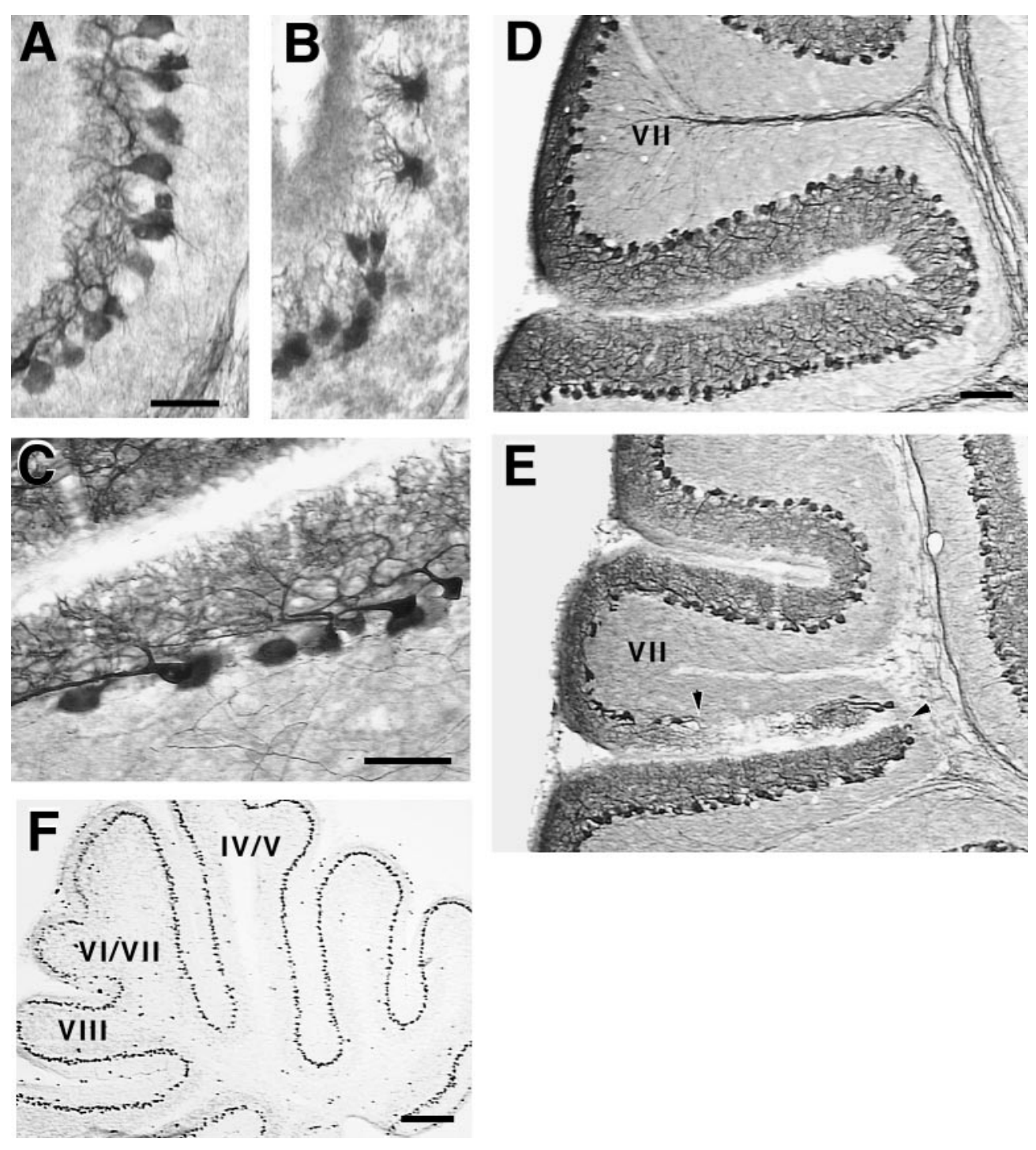

The degree of Purkinje cell loss and the general selectivity of effects on lobulation that are observed in L7En-2 mice are similar to the effects of the En-2 null mutation (Millen et al., 1994). On the surface, this would seem somewhat inconsistent. For example, in Drosophila, homeotic gene gain-of-function mutations lead in general to posterior transformations, whereas loss-of-function mutations lead to anterior transformations (Lewis, 1978; McGinnis and Krumlauf, 1992). However, it is difficult to relate in this way the En-2 knock-out data to observations described here. En-2 is normally expressed before and during the normal generation phase of Purkinje cells (from E9 on; Davis and Joyner, 1988), and the Purkinje cell deficiency in En-2 null animals is thought to occur by death or agenesis during this early time frame (Kuemerle et al., 1997). In contrast, the experiments described here most likely relate to a relatively late "patterning" event involving Purkinje cell differentiation and tissue morphogenesis (see below).

\section{Cerebellar patterning}

A double-patterning hypothesis has recently been proposed that posits two levels of involvement of En genes in cerebellar patterning (Kuemerle et al., 1997). In the first (E8-E10) event, En genes control the establishment and number of cerebellar precur- sors, and in the second, later event, cerebellar compartments are established. Although the current study can shed little additional light on the relationship of En genes to formation of the cerebellar primordium, what is clear is that the precise banding pattern of En-2 after E14.5 is not a key determinant of sagittal compartmentation. Likewise, the "position" of cerebellar fissures appears unaffected in L7En-2 animals. Rather, fissure formation and growth are selectively retarded by persistent En-2 expression in Purkinje cells. From this and other reports (Oberdick et al., 1993; Kuemerle et al., 1997; Mathis et al., 1997), it may be suggested that the patterning event that establishes both the sagittal and rostrocaudal boundaries most likely occurs during or shortly after the generation phase of Purkinje cells, sometime between E9 and E14.5. From the current work, however, it may be postulated further that patterning genes linked to the Engrailed pathway continue to play a role after this time period, mainly in the context of cerebellar growth and morphogenesis. In addition, the fissure selectivity of these morphogenetic events suggests a linkage to the earlier patterning event.

In support of these observations, genetic and biochemical evidence point toward some deterministic component to the formation of rostrocaudal divisions within the cerebellum. Generally 
Figure 7. Retarded EGL formation within cerebellar deep fissures. $A, B$, Sagittal sections of $\mathrm{P} 7$ cerebellum from wild type $(A)$ and L7En-2 mutant $(B)$ showing a thinned EGL in the vermal fissures of the mutant. Sections were stained with methyl green. Note the lack of fusion of the two sides of the EGL at the base of the fissures (arrows in B). Scale bar, $200 \mu \mathrm{m}$. $C, D$, Comparison of the EGL thickness in wild-type versus L7En-2 transgenic cerebellum in the vermis $(C)$ and hemispheres $(D)$. The EGL within wild-type and mutant cerebellar sections was divided into an equal number of segments, and its thickness along the entire cerebellar surface was determined. Note that at the base of every fissure, the thickness of the mutant EGL was thinner than in the wild type, and this effect is maximized in the fissures of the central lobe [V-VI (primary fissure), VIVII, and VII-VIII]. The two curves of each plot tend to converge at the summit of the lobules and to diverge within fissures. The values are averages of three near-midline sections and three lateral sections calculated for one cerebellum of each genotype, and these same observations were repeated in two additional P7 cerebella. Abbreviations along the $x$-axis in $D$ are defined in Table 2.
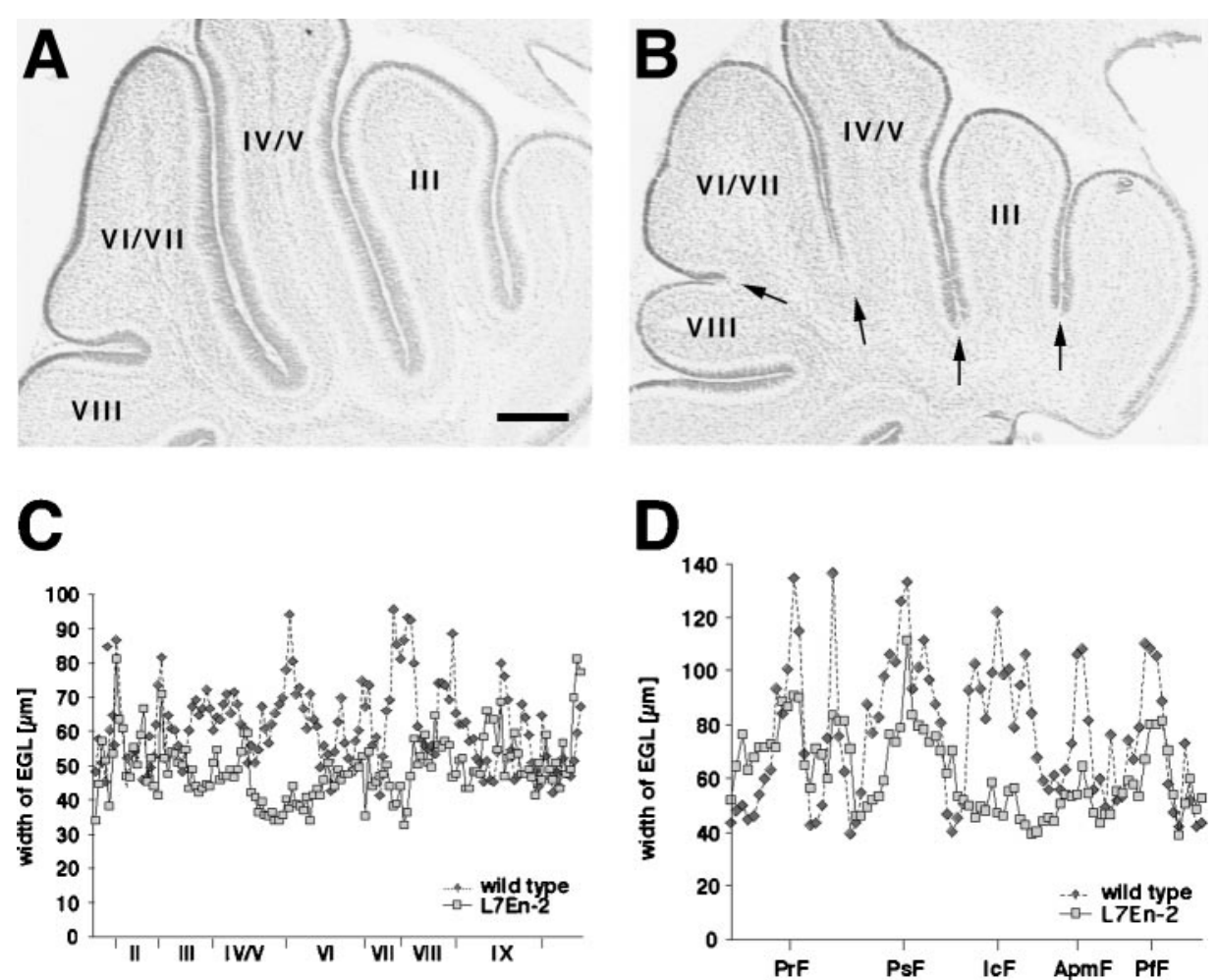

speaking, for example, the anterior and posterior lobes of the cerebellum have different embryological origins (Martinez and Alvarado-Mallart, 1989), and several mutations in mice selectively affect the survival of cerebellar cells in the anterior lobe (Herrup and Wilczynski, 1982; Ross et al., 1990). Thus, the area around the primary fissure is of great developmental significance as a transition zone between two major subdivisions of the cerebellum. Furthermore, both the genetic and biochemical evidence reveals boundaries located at or near transition zones between lobules, including but not restricted to the primary fissure. For example, mutant versions of an L7-lacZ construct show a clear boundary at the rostral edge of lobule VI at the lip of the primary fissure [see Oberdick et al. (1993), their Fig. 7], similar to the boundary revealed by a genetic lesion (leaner) (Herrup and Wilczynski, 1982; Hess and Wilson, 1991) and by at least one additional marker (gli) (Millen et al., 1995). Likewise, a transient border of zebrin expression is revealed in Lurcher mutant mice at the dorsal edge of lobule VIII, just at the lip of the fissure dividing lobules VII and VIII (Tano et al., 1992).

What is the relationship of these boundaries to the effects reported here? Because most of the cellular effects in L7En-2 cerebellum are well within selected fissures, it is unclear how they may be related to the molecular and genetic boundaries described above. In addition, to date there is no evidence of fissurerestricted expression of En genes or Wnt pathway genes, and therefore the relationship between expression of these genes, identified cerebellar boundaries, and the effects reported here may be complex. In spite of this, certain factors in addition to those discussed above indicate a "program" controlling the position and growth of fissures separating lobules and sublobules, and in this context these molecular boundaries may be significant. For example, foliation differences among different inbred mouse strains seem to be genetically encoded (Inouye and Oda, 1980; Neumann et al., 1990). In addition, from the current work, the distinct patterns of L7 $\beta$-Gal expression in sublobules VIa and VIb neatly divide lobule VI into two halves and define the position of the sublobule fissure. Despite the absence of this fissure in the L7En-2 mice, the biochemical division persists.

Thus, as can be demonstrated for lobules and sublobules alike, fissures can be shown in most cases to separate unique biochemical entities along previously existing boundaries. These boundaries can be seen during normal development before the appearance of many fissures (Oberdick et al., 1993). The main contribution of the current work is to demonstrate a molecular linkage (vis-à-vis Engrailed and its downstream targets) between a patterning event that establishes boundaries and the morphological elaboration of those boundaries in the form of fissures.

\section{Purkinje cell control of EGL formation}

One unsuspected result of persistent expression of En-2 in Purkinje cells was the transient retardation of EGL development localized within the fissures. Because this was observed in multiple lines carrying the L7En-2 construct and no expression of any transgene based on the L7 promoter has ever been detected in granule cells or in the EGL, this must be a secondary effect caused by perturbation of some property of Purkinje cells.

It has been suggested previously that matching between granule cell and Purkinje cell numbers occurs via a target-dependent process presumably mediated by a trophic property of Purkinje cells (Herrup and Sunter, 1987). In many systems, such a process of attrition follows a period of overproduction of neurons, and it has been suggested that this proliferative exuberance may allow for greater plasticity in terms of the precise size of, and the numbers of connections in, the mature nervous system (Purves, 1988). In the cerebellum, it has been proposed that Purkinje cells may also control granule cell proliferation mainly based on observations of a thinned and temporally persistent EGL in the mouse mutant staggerer (Sonmez and Herrup, 1984). More re- 
cently, direct evidence of such a Purkinje cell-EGL interaction was provided by observation of local effects on the EGL in response to spatially and temporally restricted Purkinje cell ablation by diphtheria toxin expression in transgenic mice (Smeyne et al., 1995). The current observation of EGL retardation specifically focused in the deep fissures extends the latter observations and further suggests a role for the En and Wnt pathway genes in this process. Thus, if it is accepted that fissure formation is at least partially dependent on granule cell generation during the early postnatal period (Mares and Lodin, 1970), this may be viewed as just one component of a fissurization program that is also dependent on unique subsets of Purkinje cells.

\section{Conclusions}

These observations have illustrated important ways in which cells residing in fissures differ from those located elsewhere. In addition to some previously reported differences in generation time [of vermal Purkinje cells (Inouye and Murakami, 1980) and of granule cells (Altman, 1969)], cerebellar cells in fissures are particularly sensitive to the perturbation of En and Wnt pathway signaling. These data support the view that lobulation is an active process based on unique properties of cells that reside in and around lobule junctions. Future experiments will be directed at determination of the specific molecular properties of Purkinje cells that are affected by persistent En expression and that result in the fissure-restricted effects described here.

\section{REFERENCES}

Altman J (1969) Autoradiographic and histological studies of postnatal neurogenesis. III. Dating the time of production and onset of differentiation of cerebellar microneurons in rats. J Comp Neurol 136:269-294.

Altman J, Bayer SA (1997) Development of the cerebellar system in relation to its evolution, structure, and functions. New York: CRC.

Baader SL, Schilling ML, Rosengarten B, Pretsch W, Teutsch HF, Oberdick J, Schilling K (1996) Purkinje cell lineage and the topographic organization of the cerebellar cortex: a view from $\mathrm{X}$ inactivation mosaics. Dev Biol 174:393-406.

Bian F, Chu T, Schilling K, Oberdick J (1996) Differential mRNA transport and the regulation of protein synthesis: selective sensitivity of Purkinje cell dendritic mRNAs to translational inhibition. Mol Cell Neurosci 7:116-133.

Danielian PS, McMahon AP (1996) Engrailed-1 as a target of the Wnt-1 signalling pathway in vertebrate midbrain development. Nature 383:332-334.

Davis CA, Joyner AL (1988) Expression patterns of the homeoboxcontaining genes $E n-1$ and En-2 and the proto-oncogene int-1 diverge during mouse development. Genes Dev 2:1736-1744.

Davis CA, Holmyard DP, Millen KJ, Joyner AL (1991) Examining pattern formation in mouse, chicken and frog embryos with an Enspecific antiserum. Development 111:287-298.

Herrup K, Kuemerle B (1997) The compartmentalization of the cerebellum. Annu Rev Neurosci 20:61-90.

Herrup K, Sunter K (1987) Numerical matching during cerebellar development: quantitative analysis of granule cell death in staggerer mouse chimeras. J Neurosci 7:829-836.

Herrup K, Wilczynski S (1982) Cerebellar cell degeneration in the leaner mutant mouse. Neuroscience 7:2185-2196.

Hess E, Wilson M (1991) Tottering and leaner mutations perturb transient developmental expression of tyrosine hydroxylase in embryologically distinct Purkinje cells. Neuron 6:123-132.

Inouye M, Murakami U (1980) Temporal and spatial patterns of Purkinje cell formation in the mouse cerebellum. J Comp Neurol 194:499-503.

Inouye M, Oda S (1980) Strain-specific variations in the folial pattern of the mouse cerebellum. J Comp Neurol 190:357-362.

Kuemerle B, Zanjani H, Joyner A, Herrup K (1997) Pattern deformities and cell loss in Engrailed-2 mutant mice suggest two separate patterning events during cerebellar development. J Neurosci 17:7881-7889.
Lewis EB (1978) A gene complex controlling segmentation in Drosophila. Nature 276:565-570.

Logan C, Hanks MC, Noble, Topham S, Nallainathan D, Provart NJ, Joyner AL (1992) Cloning and sequence comparison of the mouse, human, and chicken engrailed genes reveal functional domains and regulatory regions. Dev Genet 13:345-358.

Mares V, Lodin Z (1970) The cellular kinetics of the developing mouse cerebellum. II. The function of the external granular layer in the process of gyrification. Brain Res 23:343-352.

Martinez S, Alvarado-Mallart R (1989) Rostral cerebellum originates from the caudal portion of the so-called "mesencephalic" vesicle: a study using chick/quail chimeras. Eur J Neurosci 1:549-560.

Mathis L, Bonnerot C, Puelles L, Nicolas J (1997) Retrospective clonal analysis of the cerebellum using genetic laacZ/lacZ mouse mosaics. Development 124:4089-4104.

McGinnis W, Krumlauf R (1992) Homeobox genes and axial patterning. Cell 68:283-302.

McMahon AP, Bradley A (1990) The Wnt-1 (int-1) proto-oncogene is required for development of a large region of the mouse brain. Cell 62:1073-1085.

Miale IL, Sidman RL (1961) An autoradiographic analysis of histogenesis in the mouse cerebellum. Exp Neurol 4:277-296.

Millen KJ, Wurst W, Herrup K, Joyner AL (1994) Abnormal embryonic cerebellar development and patterning of postnatal foliation in two mouse Engrailed-2 mutants. Development 120:695-706.

Millen KJ, Chi-Chung H, Joyner AL (1995) A role for En-2 and other murine homologues of Drosophila segment polarity genes in regulating positional information in the developing cerebellum. Development 121:3935-3945.

Neumann PE, Mueller GG, Sidman RL (1990) Identification and mapping of a mouse gene influencing cerebellar folial pattern. Brain Res 524:85-89.

Oberdick J, Levinthal F, Levinthal C (1988) A Purkinje cell differentiation marker shows a partial sequence homology to the cellular sis/ PDGF2 gene. Neuron 1:367-376.

Oberdick J, Smeyne RJ, Mann JR, Zackson S, Morgan JI (1990) A promoter that drives transgene expression in cerebellar Purkinje and retinal bipolar neurons. Science 248:223-226.

Oberdick J, Schilling K, Smeyne RJ, Corbin JG, Bocchiaro C, Morgan JI (1993) Control of segment-like patterns of gene expression in the mouse cerebellum. Neuron 10:1007-1018.

Purves D (1988) Body and brain. Cambridge, MA: Harvard UP.

Ross ME, Fletcher C, Mason CA, Hatten ME, Heintz N (1990) Meander tail reveals a discrete developmental unit in the mouse cerebellum. Proc Natl Acad Sci USA 87:4189-4192.

Rugh R (1993) The mouse: its reproduction and development. New York: Oxford UP.

Salinas PC, Fletcher C, Copeland NG, Jenkins NA, Nusse R (1994) Maintenance of Wnt-3 expression in Purkinje cells of the mouse cerebellum depends on interactions with granule cells. Development 120:1277-1286.

Smeyne RJ, Chu T, Lewin A, Bian F, S-Crisman S, Kunsch C, Lira SA, Oberdick J (1995) Local control of granule cell generation by cerebellar Purkinje cells. Mol Cell Neurosci 6:230-251.

Sonmez E, Herrup K (1984) Role of staggerer gene in determining cell number in cerebellar cortex. II. Granule cell death and persistence of the external granule cell layer in young mouse chimeras. Dev Brain Res 12:271-283.

Sussman DJ, Klingensmith J, Salinas P, Adams PS, Nusse R, Perrimon N (1994) Isolation and characterization of a mouse homolog of the Drosophila segment polarity gene dishevelled. Dev Biol 166:73-86.

Tano D, Napieralski JA, Eisenman LM, Messer A, Plummer J, Hawkes R (1992) Novel developmental boundary in the cerebellum revealed by zebrin expression in the Lurcher $(L c /+)$ mutant mouse. J Comp Neurol 323:128-136.

Vandaele S, Nordquist DT, Fedderson RM, Tretjakoff I, Peterson AC, Orr HT (1991) Purkinje cell protein-2 regulatory regions and transgene expression in cerebellar compartments. Genes Dev 5:1136-1148.

Wurst W, Auerbach AB, Joyner AL (1994) Multiple developmental defects in Engrailed-1 mutant mice: an early mid-hindbrain deletion and patterning defects in forelimbs and sternum. Development 120:2065-2075. 